\section{O ENSINO DA LÓGICA DO JOGO DE VOLEIBOL: UMA PROPOSTA A PARTIR DO TEACHING GAMES FOR UNDERSTANDING E DO USO DE TECNOLOGIAS}

\author{
TEACHING VOLLEYBALL LOGIC: A PROPOSAL BASED ON TEACHING \\ GAMES FOR UNDERSTANDING AND THE USE OF TECHNOLOGIES
}

\author{
LA ENSEÑANZA DE LA LÓGICA DEL JUEGO DE VOLEIBOL: \\ UNA PROPUESTA A PARTIR DEL TEACHING GAMES FOR \\ UNDERSTANDING Y DEL USO DE TECNOLOGÍAS
}

Carina Lara Sarruge*, Guy Ginciene ${ }^{\star *}$, Fernanda Moreto Impolcetto*
Palavras chave: Voleibol. Tecnologia da Informação.

Ensino.

Esportes.
Keywords: Volleyball. Information Technology. Teaching. Sports.

Palabras clave: Voleibol. Tecnología de la Información. Enseñanza. Deportes.
Resumo: Esta pesquisa teve por objetivo analisar a utilização do Teaching Games for Understanding (TGfU) e das Tecnologias da Informação e Comunicação (TIC) como recursos didáticos no processo de iniciação esportiva do voleibol. Optou-se por uma abordagem qualitativa e a realização de duas etapas: um levantamento diagnóstico com professores de voleibol para identificar as dificuldades táticas dos alunos; elaboração e implementação de uma Unidade Didática em turma de iniciação. Os resultados indicaram que as TIC - em especial a filmagem - em conjunto com o modelo TGfU contribuíram para alcançar os objetivos de ensino, em especial para a compreensão dos elementos táticos do jogo. Concluiu-se que mesmo com dificuldades vivenciadas no decorrer das aulas, muitos alunos adquiriram capacidade de jogar intencionalmente de acordo com os princípios táticos ensinados

Abstract: This research analyzed the use of Teaching Games for Understanding (TGfU) and Information and Communication Technologies (ICT) as teaching resources in the process of initiation in volleyball. It employed a two-step qualitative approach: a diagnostic survey with volleyball teachers to identify students' tactical challenges; designing and implementing a teaching unit in the initiation group. The results indicated that ICT - particularly the filming aspect - together with the TGfU model contributed to achieve the teaching goals, especially to understand the tactical elements of the game. The study found that even with difficulties experienced during the lessons, many students acquired the ability to play intentionally according to the tactical principles taught.

Resumen: Esta investigación tuvo por objetivo analizar la utilización del Teaching Games for Understand (TGfU) y de las Tecnologías de la Información y Comunicación (TIC) como recursos didácticos en el proceso de iniciación deportiva del voleibol. Se optó por un enfoque cualitativo y la realización de dos etapas: un levantamiento diagnóstico con profesores de voleibol para identificar las dificultades tácticas de los alumnos, y la elaboración e implementación de una Unidad Didáctica en clase de iniciación. Los resultados indicaron que las TIC - en especial las filmaciones - en conjunto con el modelo $T G f U$ contribuyeron a alcanzar los objetivos de enseñanza, en especial para la comprensión de los elementos tácticos del juego. Se concluyó que incluso con dificultades vividas en el curso de las clases, muchos alumnos adquirieron capacidad de jugar intencionalmente de acuerdo con los principios tácticos enseñados.
* Universidade Estadual Paulista Júlio de Mesquita Filho. São Paulo, SP, Brasil.

E-mail:

ca_lara@yahoo.com.br;

fe_moreto@yahoo.com.br

** Universidade Federal do Rio Grande do Sul. Porto Alegre, RS, Brasil.

E-mail:

guy.ginciene@ufrgs.br

Recebido em: 13-03-2019 Aprovado em: 09-01-2020 Publicado em: 11-02-2020 


\section{INTRODUÇÃO}

O voleibol se tornou uma modalidade muito conhecida e praticada no Brasil desde a década de 1980. No entanto, algumas características de seu jogo acentuam a dificuldade de ensiná-lo, como é o caso da impossibilidade de retenção da bola (HIRAMA et al., 2015; IMPOLCETTO; DARIDO, 2011). Ao não poder segurar a bola, o aprendiz, precisa tomar rápidas decisões sobre como (gesto técnico) e onde (a intenção tática) rebater (GONZÁLEZ; BRACHT, 2012; MAHLO, 1980). Diante desse desafio, é comum que o processo de ensino seja normalmente centrado e iniciado na técnica (HIRAMA et al., 2015), a fim de resolver a principal dificuldade vivenciada pelos alunos durante a iniciação: o gesto técnico.

O ensino tradicional do voleibol, portanto, normalmente baseia-se na fragmentação de suas partes para facilitar a memorização e promover a repetição dos movimentos (BAYER, 1994; GALATTI et al., 2014), mesmo que muitas vezes esse ensino esteja descontextualizado do objetivo do jogo (GALATTI et al., 2014). Além disso, o processo também é centrado na transmissão de um conhecimento em que os alunos são apenas executantes das tarefas que lhes são determinadas e têm como objetivo acumular informações demonstradas pelo professor (SCAGLIA; REVERDITO; GALATTI, 2014).

Um dos problemas dessa perspectiva de ensino é que a lógica interna (GONZÁLEZ; BRACHT, 2012; PARLEBAS, 2001) do voleibol - enviar a bola para o outro lado de forma a dificultar ou impedir a devolução do adversário - acaba sendo desconsiderada durante a aprendizagem. Assim, o aluno aprende o "como fazer" (executar a manchete, cortada e o toque), mas não necessariamente aprende "o que" fazer com esse conjunto de movimentos durante um jogo (KIRK; MACPHAIL, 2002; MITCHELL; OSLIN; GRIFFIN, 2013; THORPE; BUNKER; ALMOND, 1986).

Vale destacar que o gesto técnico no voleibol é sempre acompanhado de uma intenção tática (GONZÁLEZ; BRACHT, 2012), ou seja, mais do que executar uma cortada, é necessário compreender o jogo e saber executá-la de forma a dificultar ou impedir a devolução adversária (BORGES; DINIZ, 2017). É no sentido de superar esses problemas do ensino tradicional que muitas abordagens foram desenvolvidas e estudadas ao longo dos anos (HARVEY; JARRETT, 2013; MITCHELL; OSLIN; GRIFFIN, 2013; REVERDITO; SCAGLIA; PAES, 2009).

Dentre essas abordagens está o Teaching Games for Understanding (TGfU), que tem entre seus objetivos o ensino por meio da compreensão (THORPE; BUNKER; ALMOND, 1986) e a inserção do aluno no centro do processo de aprendizagem (HARVEY; JARRETT, 2013; HARVEY; PILL; ALMOND, 2018; HASTIE; MARTINEZ DE OJEDA; CALDERÓN LUQUIN, 2011). Em outras palavras, se no ensino tradicional se aprendia apenas o "como fazer" (a execução correta de uma técnica), no TGfU a ideia é ensinar "o que" e "quando" fazer no jogo, para que o ensino da técnica se torne mais significativo e contextualizado a ele.

A capacidade do professor/treinador em questionar os alunos também é fator primordial no TGfU. Por isso, planejar perguntas relevantes a partir dos objetivos de ensino, focar na capacidade dos alunos em solucionar um problema tático e encorajá-los a refletir, analisar e verbalizar uma solução, são ações fundamentais (CLEMENTE, 2014; COSTA et al., 2010; PEARSON; WEBB, 2008). 
Para conceber um processo significativo de aprendizagem, é preciso pedagogizar o ensino - favorecer a construção do conhecimento e a promoção de interação com o que o aluno já sabe - processo que deve ser mediado, intencionalmente, por um pedagogo do esporte (SCAGLIA; REVERDITO; GALATTI, 2014). O professor e/ou treinador de esportes, portanto, parece ter um papel fundamental, já que é ele quem vai construir sua própria prática pedagógica, além de desenvolver seus afazeres por meio de princípios metodológicos e recursos educacionais mais relevantes e significativos para seu contexto.

Dentre esses recursos educacionais existentes, as Tecnologias da Informação e Comunicação (TIC) se apresentam como uma possibilidade atual, inclusive para as áreas da Educação Física e do Esporte. Diversos estudos têm sido realizados para verificar as barreiras e as potencialidades das TIC (BIANCHI; PIRES, 2010; BODSWORTH; GOODYEAR, 2017; LUGUETTI; GOODYEAR; ANDRÉ, 2017). Entretanto, ainda são poucos os estudos que procuraram conhecer e analisar a articulação entre as TIC e o TGfU durante o processo de ensino. Diante do exposto, o objetivo desta pesquisa foi analisar a utilização do TGfU e das TIC como recursos didáticos no processo de iniciação esportiva do voleibol.

\section{CAMINHOS METODOLÓGICOS}

Para atingir o objetivo proposto, optou-se por uma abordagem qualitativa, com referencial teórico na pesquisa participante (LAKATOS; MARCONI, 2003). Antes da seleção das TIC e dos elementos do TGfU que seriam utilizados na Unidade Didática (UD), realizou-se um (a) levantamento diagnóstico com professores de voleibol do SESC São Paulo para definição dos objetivos. Em decorrência dos dados obtidos, seguiu-se para a (b) elaboração e implementação de uma UD de iniciação ao voleibol.

\subsection{LEVANTAMENTO DIAGNÓSTICO}

Num primeiro momento 12 professores do SESC São Paulo que atuam com turmas do Esporte Jovem (equivalentes à que participou desta pesquisa), na modalidade voleibol, responderam um questionário semiestruturado composto por perguntas que buscaram investigar suas percepções sobre as ações mais e menos realizadas pelos alunos. A seleção das perguntas foi elaborada pelos pesquisadores, à partir de suas experiências pedagógicas, dentre as ações que consideravam mais difíceis dos alunos executarem. O questionário foi validado por quatro professores doutores que trabalham com metodologias do ensino dos esportes coletivos no Ensino Superior e possuem publicações nessa área.

O questionário foi constituído de cinco itens cujas respostas seguem uma escala tipo Likert, usada para medir concordância de pessoas sobre determinadas afirmações (SILVA JÚNIOR; COSTA, 2014). A pontuação referente às respostas eram: (1) Nunca, (2) Raramente, (3) Às vezes e (4) Sempre. Obteve-se o retorno de 12 professores $(P)$ de um total de 13.

A pontuação das respostas foi obtida através da soma dos valores de cada um dos cinco itens. A soma dos itens que alcançaram as pontuações mais baixas indicaram as ações menos realizadas pelos alunos e consequentemente os temas a serem elaborados na UD (Tabela 1). 
Tabela 1 - Resposta dos professores relacionadas às ações realizadas pelos alunos

\begin{tabular}{|c|c|c|c|c|c|c|c|c|c|c|c|c|c|}
\hline Ações realizadas & P 1 & P 2 & P3 & P4 & P5 & P6 & P7 & P8 & P9 & P10 & P11 & P12 & Total \\
\hline $\begin{array}{l}\text { A- Ocupar os } \\
\text { espaços vazios }\end{array}$ & 4 & 3 & 3 & 3 & 2 & 3 & 3 & 3 & 2 & 3 & 3 & 2 & 34 \\
\hline $\begin{array}{l}\text { B- Observar os } \\
\text { espaços vazios }\end{array}$ & 3 & 2 & 2 & 2 & 2 & 1 & 3 & 2 & 3 & 2 & 2 & 3 & 27 \\
\hline $\begin{array}{l}\text { C- Direcionar a } \\
\text { bola nos espaços } \\
\text { vazios }\end{array}$ & 3 & 2 & 2 & 2 & 2 & 2 & 3 & 2 & 2 & 2 & 1 & 3 & 26 \\
\hline D- Rodízio & 4 & 4 & 4 & 4 & 3 & 4 & 4 & 4 & 4 & 4 & 3 & 4 & 46 \\
\hline $\begin{array}{l}\text { E- Relação } \\
\text { bloqueio e rede }\end{array}$ & 3 & 3 & 3 & 3 & 2 & 3 & 3 & 2 & 2 & 3 & 1 & 3 & 31 \\
\hline
\end{tabular}

Fonte: Elaborado pelos autores.

Segundo os professores, o que os alunos menos realizavam durante o jogo de voleibol eram "observar os espaços vazios" e "direcionar a bola nos espaços vazios".

\subsection{ELABORAÇÃO E IMPLEMENTAÇÃO DA UD}

Foram elaboradas 10 horas/aula (cinco encontros de duas horas) com foco nos elementos táticos anteriormente destacados. A turma era composta por 24 alunos (13 meninos e 11 meninas) entre 13 e 17 anos que participavam do Programa Esporte Jovem Vôlei.

Os elementos tecnológicos selecionados para apoiar o desenvolvimento da Unidade Didática foram: Tablet (filmagem); Celular (filmagem e comunicação com os alunos); Windows Movie Maker (edição de vídeo); projetor (exibição dos vídeos); Kahoot (análise de jogadas); aplicativo Slow Motion FX (filmagem e compartilhamento em câmera lenta); Whatsapp (compartilhamento de vídeos e fotos).

As aulas foram baseadas no modelo TGfU cujos autores, Thorpe, Bunker e Almond (1986), apontam seis fases:

A Forma de jogo, baseia-se em quatro princípios pedagógicos: (1) amostragem de jogos selecionados, para confrontar os alunos com a prática de jogos com problemas distintos; (2) modificação por representação, com a manipulação da complexidade do jogo formal a fim de torná-lo mais simples, sem mudar as estruturas táticas; (3) modificação por exagero, para colocar o aluno em determinado problema tático e (4) complexidade tática, na qual se acrescentam variáveis nas formas de jogo (THORPE; BUNKER; ALMOND, 1986).

A apreciação do jogo, refere-se à compreensão das regras e da natureza do jogo pelos alunos e na fase da consciência tática os alunos são desafiados a entender o jogo para poder praticá-lo ou permitir observá-lo (CLEMENTE, 2014). Em seguida eles podem fazer a tomada de decisão, que necessita de um questionamento eficaz do professor, a fim de que melhorem seus desempenhos a partir da decisão "do que fazer" e "como fazer" (PEARSON; WEBB, 2008; SOUZA, 1996).

Somente depois do aluno compreender esse processo é que ele vai aperfeiçoar a execução motora. Os autores do modelo não aceitam que o refinamento da 
técnica venha antes da compreensão da tática. Finalmente, o aluno chega na etapa da performance, habilitado para desempenhar seu melhor papel no jogo (THORPE; BUNKER; ALMOND, 1986).

Como o TGfU não é um modelo engessado, a sequência de aulas foi estruturada e adaptada às condições da turma e objetivo da UD (Quadro 1), com finalidades específicas em cada aula (Quadro 2).

Quadro 1 - Estrutura de um plano de aula

\begin{tabular}{|c|}
\hline Jogo inicial e/ou análise da aula anterior \\
\hline Conscientização Tática \\
\hline Tarefas \\
\hline Conscientização Tática/ Tomada de decisão \\
\hline Jogo Formal \\
\hline
\end{tabular}

Fonte: Elaborado pelos autores

Quadro 2 - Objetivos de cada aula

\begin{tabular}{|c|c|}
\hline $1^{\mathrm{a}}$ aula & $\begin{array}{l}\text { Identificar os objetivos do vôlei/ Olhar para quadra adversária em todos os momentos } \\
\text { que for passar a bola. }\end{array}$ \\
\hline $2^{\mathrm{a}}$ aula & $\begin{array}{l}\text { Identificar e explorar os espaços que surgem na quadra adversária a partir do } \\
\text { posicionamento dos jogadores no momento do saque da sua equipe e da recepção da } \\
1^{\mathrm{a}} \mathrm{bola}^{1} .\end{array}$ \\
\hline $3^{a}$ aula & $\begin{array}{l}\text { Identificar e explorar os espaços que surgem na quadra adversária a partir do } \\
\text { posicionamento dos jogadores na } 2^{\mathrm{a}} \text { bola }{ }^{2} \text {. }\end{array}$ \\
\hline $4^{a}$ aula & $\begin{array}{l}\text { Identificar e explorar os espaços que surgem na quadra adversária a partir do } \\
\text { posicionamento dos jogadores na } 3^{a} \text { bola }^{3} \text {. }\end{array}$ \\
\hline $5^{\mathrm{a}}$ aula & $\begin{array}{c}\text { Relembrar todos os espaços que surgem na quadra adversária em todas as bolas e } \\
\text { direcionar nesses lugares. }\end{array}$ \\
\hline
\end{tabular}

Fonte: Elaborado pelos autores

Nessa perspectiva, a primeira parte da aula foi sempre o jogo inicial e/ou análise da aula anterior. Na primeira aula da UD, os alunos realizaram um jogo, que foi filmado e em seguida exibido numa tela. No início das aulas seguintes (dois, três e quatro), eles visualizaram em grupo a filmagem, editada através do Windows Movie Maker, do último jogo formal realizado nas aulas anteriores.

Além disso, na terceira aula, três lances foram filmados e gravados em câmera lenta com o aplicativo Slow Motion FX, enviados por whatsapp e vistos no início da aula seguinte. No final da quarta aula, foi utilizada a plataforma Kahoot para um quiz de perguntas, com o intuito de auxiliar no reconhecimento e análise das jogadas.

Todos os jogos iniciais assistidos em grupo, serviram para que os alunos se observassem e isso auxiliasse na fase de conscientização tática. Questões foram feitas a fim de subsidiar discussões e reflexões a respeito da compreensão do jogo.

\footnotetext{
$11^{\text {a }}$ bola: É o primeiro toque que a equipe faz quando a bola vem do lado adversário, podendo ser uma recepção de saque, uma defesa de ataque ou contra-ataque. Normalmente é enviada para o levantador.

$22^{a}$ bola: É o segundo toque que a equipe faz depois de receber a bola. Normalmente é a bola que o levantador passa para um atacante.

$33^{a}$ bola: É o último toque que uma equipe pode fazer antes de passar para o lado adversário. Normalmente acontece em forma de cortada, após um passe e um levantamento.
} 
A maioria delas foram elaboradas previamente para que elementos fundamentais não ficassem de fora. $O$ intuito foi o de conduzir os alunos a analisarem criticamente suas atuações durante o jogo, promovendo uma compreensão e conhecimento mais abrangente acerca da lógica do mesmo (BOLONHINI; PAES, 2009).

Na sequência ocorriam as tarefas das aulas. Para esse momento os jogos utilizados foram sempre modificados, elaborados com referência nos princípios pedagógicos do TGfU (CLEMENTE, 2012; GRAÇA; MESQUITA, 2007; THORPE; BUNKER; ALMOND, 1986):

a) Amostragem de jogos selecionados: todos os jogos propostos tinham tarefas diferentes para os alunos executarem, a fim de estimulá-los a resolver variados problemas.

b) Modificação por representação: alguns dos jogos propostos foram os reduzidos, mas mantendo-se princípios táticos do jogo formal, com objetivos simples para que os alunos pudessem entrar em contato com situações específicas.

c) Modificação por exagero: as regras eram colocadas de modo a canalizar a atenção dos alunos para a resolução de uma circunstância singular, como por exemplo, somente poder fazer um ponto se fosse de $2^{\mathrm{a}}$ bola.

d) Complexidade tática: os problemas táticos colocados foram previamente pensados considerando o nível de compreensão dos alunos e sempre aumentando a complexidade, na medida que a compreensão acontecia.

Ao final de cada jogo ou quando notava-se que os alunos estavam com dificuldade na execução do mesmo ou tarefa proposta, acontecia uma pausa para questionamentos e retomada da conscientização tática, a fim de instigá-los a descobrirem uma solução adequada.

Nessa pausa acontecia também um processo de tomada de decisão, para conduzir o aluno a conhecer as formas de abordar o problema e as maneiras de solucioná-lo (CLEMENTE, 2014). Perguntas sobre "o que fazer" apareceram ao longo da UD, como: Em quais espaços a bola pode cair com mais facilidade? É possível enviar a bola de modo a dificultar a recepção, se conseguirem olhar para a quadra adversária? E questões relativas ao "como fazer": que formas de passar a bola para o lado oposto dificultariam a recepção/defesa da outra equipe? Qual o melhor tipo de saque a se fazer nesse jogo?

Depois das decisões anteriores, chegavam à fase de execução motora, ou seja, voltavam para o jogo e tentavam fazer o que tinham acabado de discutir. Assim, experimentavam novas formas de executar um movimento, dessa vez com intencionalidade, procurando aliar o gesto técnico (como fazer) à tática individual (o que fazer).

A última parte da aula foi destinada ao jogo formal. Pelos pressupostos do TGfU esse momento é um dos mais importantes, pois é por meio dele que o aluno, após a percepção do "o que" e "como" fazer, pode concretizar o que foi pensado e treinado anteriormente através de desafios táticos mais complexos (SOUZA, 1996).

\subsection{COLETA E ANÁLISE DOS DADOS}

Durante as aulas foram realizadas observações participantes e o registro das informações num diário de campo acontecia ao final das mesmas (SPARKES; SMITH, 
2014). Como indicado por Bogdan e Biklen (1994), foi relatado por escrito aquilo que os investigadores ouviram, viram e pensaram no decorrer do levantamento dos dados, com foco no uso do TGfU e das TIC.

Ao final da implementação foram selecionados seis alunos (que tiveram presença na maioria das aulas, com divisão igualitária de gênero) para participar de uma sessão de grupo focal, orientada por um roteiro de perguntas pré-estabelecidas (DAMICO, 2006). O encontro foi gravado em vídeo e áudio, moderado por uma das pesquisadoras, que estimulou os/as participantes a expressarem livremente seus sentimentos, experiências e opiniões sobre a UD.

Os dados da pesquisa - diário de campo e sessão de grupo focal - foram transcritos e passaram por uma análise de conteúdo, por meio das seguintes etapas: pré-análise, exploração do material ou codificação e tratamento dos resultados obtidos/interpretação (MINAYO, 2007).

Na etapa de pré-análise, realizou-se a leitura flutuante das páginas transcritas, por meio das quais formulou-se hipóteses e pressupostos iniciais relacionados ao tema do estudo. Na segunda etapa, características comuns foram evidenciadas, reunidas em unidades e elencadas a partir de pontos em comum. Após essa exploração, as unidades com características em comum foram nomeadas. A última etapa compreendeu o tratamento dos resultados, inferência e interpretação. Buscouse colocar em evidência informações importantes, como o que aparecia com mais frequência na análise, o que resultou em duas grandes categorias: o ensino do voleibol a partir do TGfU; a filmagem e as TIC no ensino do voleibol.

Todos os alunos assinaram um Termo de Assentimento para participação do estudo, bem como seus pais e/ou responsáveis um Termo de Consentimento Livre e Esclarecido. O projeto foi submetido ao Comitê de Ética em Pesquisa em Seres Humanos e recebeu aprovação, por meio do parecer $n^{\circ}$ 1.815.367.

\section{O ENSINO DO VOLEIBOL A PARTIR DO TGfU}

Nos resultados dessa categoria, duas subcategorias, relacionadas às características das abordagens centradas no jogo e na proposta do TGfU foram identificadas e analisadas: atividades com interação entre os adversários; estímulo à reflexão e verbalização sobre "o que" fazer (GONZÁLEZ; BRACHT, 2012).

\subsection{ATIVIDADES COM INTERAÇÃO ENTRE OS ADVERSÁRIOS}

A mudança na configuração das aulas, em especial na utilização de atividades com interação entre os adversários ocasionou um certo estranhamento por parte dos alunos. Um exemplo disso foi observado logo no início da UD, em uma atividade que tinha por objetivo direcionar a bola para um adversário com cor específica de colete: "Eles confundiam se era para passar em quem estava com a cor escolhida ou se quem estava com a cor deveria fazer o passe. No início foi um caos que aos poucos foi se organizando" (Diário de campo, 8 de agosto de 2017).

Para além de estarem acostumados a um modelo diferente de ensino, as regras utilizadas nos jogos para enfatizar alguns elementos táticos, requeriam um tempo maior para experimentação e compreensão da lógica proposta: "Eu notava que na fila um ia explicando para o outro [...] Em alguns momentos, alguns alunos 
paravam e diziam 'espera, deixa eu entender', falando sozinhos, olhando para a quadra e parecendo desenhar mentalmente o jogo" (Diário de campo, 8 de agosto de 2017).

Essa reação de estranheza pode ter sido ocasionada pela mudança da configuração das aulas. No modelo tradicional, os alunos simplesmente executam as ações solicitadas pelos professores/treinadores. Nessa nova lógica, o professor oferece situações problemas, estimulando os alunos a uma série de ajustes importantes na formação técnica e tática, sendo então protagonistas das suas ações (HIRAMA et al., 2015).

Nesse tipo de estratégia pedagógica, os jogos propostos são adaptados com regras e espaços diferentes para que os problemas táticos conduzam à determinadas soluções táticas e técnicas. Explica-se: em uma atividade tradicional para o ensino do voleibol, os alunos realizariam exercícios repetidos de passes para um alvo (parede, colega ou cone), sem que existisse a imprevisibilidade do jogo de voleibol. Assim, eles precisariam apenas se concentrar para executar um movimento e acertar a bola em um determinado local, sem que ninguém atrapalhasse essa ação (situação estável).

Já no modelo de ensino utilizado na UD (com exemplo nesta atividade de direcionamento da bola), os jogadores deveriam agir de maneira imprevisível, logo o jogador responsável por passar/atacar deveria: adequar sua ação de acordo com a bola que recebia do levantador; o levantador dependia do tipo de passe que recebia; e o passador dependia de onde o adversário havia enviado a bola. Ou seja: a bola nem sempre chegava no mesmo lugar e da mesma forma para o atacante. Para além disso, este atacante deveria observar os adversários - em especial o de colete - antes de executar o movimento para enviar a bola ao outro lado da rede. Além das demandas técnicas existentes para conseguir realizar essas ações, os alunos precisavam resolver demandas táticas individuais e em grupo, estimulados sempre a construir suas próprias aprendizagens, valorizando os processos cognitivos de percepção, tomada de decisão e a compreensão do jogo (COSTA et al., 2010; MESQUITA; PEREIRA; GRAÇA, 2009).

Com o tempo, eles se acostumaram com essa configuração das aulas, se adaptaram e passaram a opinar mais do que de costume, como observou-se nessa sugestão de um aluno: "Professora, tá muito difícil, eles passam a bola direto, deveria ter que ser obrigação dar três toques" (Informação verbal do aluno, 2017). Esse é um aspecto muito importante do TGfU, o qual incentiva o aluno a participar criticamente na elaboração das atividades, avaliando o seu próprio desempenho e assim estabelecer ricas e complexas redes de relações no contexto da aula (BOLONHINI; PAES, 2009).

\subsection{ESTÍMULO À REFLEXÃO E VERBALIZAÇÃO SOBRE "O QUE” FAZER}

A consciência tática perpassa a lógica do voleibol e pode ser vista com dois planos de referência: no plano regulamentar, através das especificidades das regras; e no plano das relações entre equipe e adversário (ROCHA, 2009).

No plano das regras, os alunos foram questionados com perguntas que, a princípio podem parecer simples, mas muitas vezes as respostas necessitaram de elaboração coletiva. Em um dos primeiros questionamentos, registrado no diário de campo, observa-se: "[quando perguntou-se para o grupo qual era o objetivo do jogo de vôlei] "Alguns disseram que era passar a bola para o outro lado da quadra" (Diário 
de Campo, 8 de agosto de 2017). No entanto, segundo a lógica do voleibol, para além de passar a bola, o objetivo é dificultar a devolução adversária (BORGES; DINIZ, 2017). A indagação continuou: "Mas se passar a bola para o outro lado e a outra equipe também devolver a bola, como vai terminar o jogo?". "Como podemos fazer ponto então?". As respostas foram aparecendo na medida em que se estimulava a reflexão: "jogando a bola no chão adversário, se alguém errar, se alguém der dois toques ou encostar na rede" (Diário de Campo, 8 de agosto de 2017). Chegou-se à conclusão coletiva de que direcionar a bola no jogador menos habilidoso ou nos espaços vazios favoreceria as chances de pontos.

Em seguida, os alunos foram questionados sobre os motivos para eles não olharem para o outro lado da quadra quando passavam a bola. Um deles respondeu: "porque a gente se preocupa só em passar a bola para o outro lado, meio que se livrar logo dela" (Diário de Campo, 8 de agosto de 2017). Os colegas concordaram e apresentaram outros possíveis motivos, como: receio de errar; medo de passar a bola de forma incorreta; falta de confiança; quando na posição de levantador, medo dos atacantes brigarem por não ter recebido a bola.

$\mathrm{Na}$ aula em que uma das tarefas consistia no ponto de saque valer três, observou-se que os alunos pouco olhavam para a outra quadra antes de sacar. Os sacadores foram questionados em qual posição tinham intenção de sacar e por quê. As respostas demonstraram que eles sabiam o local que dificultaria a recepção da equipe adversária, no entanto, a falta de costume de olhar para o outro lado e de um incentivo para isso fazia com que eles não tivessem essa atitude. A partir da intervenção efetuada, os pontos começaram a ser marcados por meio da solução tático-técnica encontrada. Notou-se que ao serem incentivados, os alunos se tornaram mais conscientes taticamente e puderam tomar melhores decisões no jogo. Então, ao pensarem estrategicamente sobre os conceitos do jogo, eles desenvolveram habilidades dentro do contexto real (PEARSON; WEBB, 2008).

Adquirir essa consciência é fator estruturante na forma de jogar, que permite aos alunos serem melhores jogadores a partir do desenvolvimento da sua compreensão do jogo e menos dependentes do professor nas tomadas de decisões (SOUZA; MÜLLER; COSTA, 2014). É um recurso de tamanha importância, que foi registrado com evidência em muitas passagens do diário de campo, como numa situação na qual os alunos foram questionados sobre o melhor momento de surpreender o adversário com uma bola passada no $1^{\circ}$ ou $2^{\circ}$ toque da equipe. Alguns responderam no saque, outros perceberam que no rali existe maior possibilidade de surpreender o adversário.

Considera-se que esse exercício de pensar e repensar estratégias foi relevante, pois permitiu aos alunos elaborar hipóteses mentais, que aos poucos foram sendo verbalizadas e discutidas com os colegas. Observou-se ainda um aumento no número de alunos que emitiam opiniões, pois, além de ficarem mais à vontade para falar, começaram a compreender mais o jogo e melhorar o conhecimento tático o que também favoreceu o protagonismo dos mesmos nas aulas.

\section{A FILMAGEM E AS TIC NO ENSINO DO VOLEIBOL}

Um dos recursos utilizados durante as aulas foi a filmagem dos alunos no jogo formal, para posterior análise e discussão coletiva de situações específicas. O 
jogo final da primeira aula, por exemplo, foi filmado com o propósito de verificar se alguém havia olhado para a quadra adversária antes de passar a bola. Já na quarta aula o intuito foi observar se algum jogador conseguia usar com eficácia a $1^{\mathrm{a}}$ e a $2^{\mathrm{a}}$ bola para o ataque.

No início das análises dos vídeos, notou-se que os alunos faziam muitas observações, exceto sobre a posição que eles assumiam em quadra. Com o decorrer das aulas, eles passaram a focar mais no objetivo proposto. O vídeo em câmera lenta ajudou nesse processo. Entre as observações realizadas, verificou-se que ninguém olhava para a quadra adversária antes de sacar, com exceção de um único aluno. Em outro momento, foi possível perceber também que, em relação à $1^{\text {a }}$ bola, havia muito erro de posicionamento durante a fase defensiva. Na avaliação dos alunos, o uso da filmagem e a posterior visualização em grupo ajudou na aprendizagem de diversos aspectos, tais como:

Eu achei que foi uma forma mais fácil de visualizar, a entender a teoria (Informação verbal - aluno 5, 2017).

O ver no projetor eu consigo entender melhor, onde tem espaço, onde que não tem (Informação verbal - aluno 2, 2017).

Ainda sobre a aprendizagem dos alunos, foi possível identificar que parte conseguiu observar os espaços na quadra adversária com visualização da filmagem. Já outros necessitaram também de uma explicação na própria quadra de jogo. Entende-se que esses dois recursos se complementaram para a aprendizagem dos elementos táticos. Betti e Mendes (2016) apontam que as linguagens utilizadas durante o processo de ensino não são suprimidas pelo aprendiz, mas podem ser incorporadas e por vezes hibridizadas às novas formas de linguagens. Logo, utilizar artifícios como as TIC e os vídeos, associados aos modelos de ensino já familiarizados pelos alunos, pode ser uma estratégia eficiente.

Destaca-se outra estratégia de ensino com a utilização da filmagem. No jogo final da segunda aula, foram filmados três lances nos quais o passe chegou à mão do levantador, a fim de identificar o posicionamento do adversário quando a bola estava com esse jogador. As jogadas foram gravadas com o recurso do aplicativo Slow Motion FX, que filma, salva na velocidade desejada e pode ser compartilhado pelo whatsapp.

Em casa, os alunos deveriam olhar e se necessário pausar o vídeo quando a bola estava na mão do levantador, marcar o posicionamento do adversário nas quadras desenhadas em uma ficha de avaliação e circular os maiores espaços que sobravam em quadra. Os três lances foram enviados no grupo do whatsapp e solicitou-se a seguinte tarefa: os alunos deveriam individualmente desenhar sua resposta no papel, tirar uma foto e enviá-la somente para a professora. 
Figura 1 - Tarefa enviada por whatsapp.

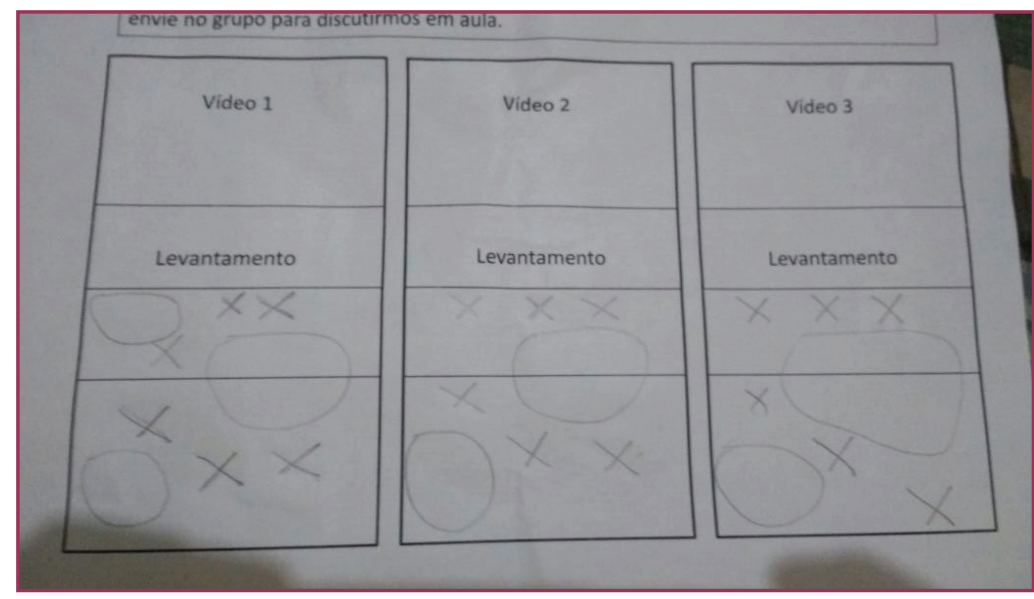

Fonte: Acervo pessoal.

Todos os alunos que participaram do grupo focal enviaram a tarefa e relataram que foi bastante proveitosa. Essa estratégia possibilitou que os alunos observassem e se conscientizassem sobre o elemento tático.

Outro recurso utilizado foi um quiz digital por intermédio da plataforma online Kahoot. O quiz foi projetado num telão com questões para que os alunos, após analisarem determinadas jogadas, indicassem os espaços vazios na quadra . Foram utilizadas imagens de jogos filmados em aula, situações de jogos retirados do youtube e figuras com posicionamento desenhado. Essa ferramenta favoreceu a aprendizagem do grupo, pois fixou o conteúdo aprendido, promoveu engajamento e motivação, aspectos indicados pelos próprios alunos no grupo focal.

\section{CONSIDERAÇÕES FINAIS}

Apesar do estranhamento dos alunos no início da UD, inseri-los no centro do processo de aprendizagem - por meio de atividades com interação entre os adversários, pela constante busca de reflexão e verbalização das soluções táticas contribuiu sobremaneira para atingir os objetivos de ensino estabelecidos.

Os recursos das TIC - em especial a filmagem - em conjunto com o modelo do TGfU também contribuíram nesse processo, especialmente para a compreensão dos elementos táticos do jogo. Os vídeos, aliados à experiência prática, foram imprescindíveis para que os alunos: entendessem a lógica do voleibol; aprendessem a reconhecer os espaços vazios na quadra adversária, verificar o melhor momento $\left(1^{a}, 2^{a}\right.$ e $3^{a}$ bola) e a melhor forma de passar a bola (toque, manchete, cortada).

As filmagens dos jogos feita pelo celular ou tablet, a posterior visualização (projeção no telão, envio por whatsapp em câmera lenta) e a participação no quiz - foram o ponto chave das TIC, que ajudaram a potencializar um dos principais elementos do TGfU: a fase de conscientização tática. Esses recursos permitiram melhor visualização da tomada de decisão, os alunos puderam assistir e pensar sobre a própria atuação para tomar decisões sobre "o que fazer" nas diversas situações de jogo.

Essa aprendizagem pôde ser observada no último jogo da UD, no qual $43 \%$ das disputas de pontos tiveram alunos atuando com clara intenção de direcionamento da 
bola. Mesmo com as dificuldades e limitações apresentadas no decorrer das aulas, muitos adquiriram capacidade de jogar intencionalmente de acordo com os princípios táticos do voleibol.

Observa-se que trabalhos sobre planejamento e sistematização de aulas de vôlei, com referencial no ensino a partir da lógica da modalidade são reduzidos na área. Nesse sentido, aponta-se para a necessidade de novos estudos e em outros contextos, mas também para uma aproximação com a prática pedagógica, que alcance professores e técnicos de voleibol, por meio de publicações de artigos e livros ou por outros veículos de divulgação como sites e blogs.

\section{REFERÊNCIAS}

BAYER. Claude. O ensino dos desportos colectivos. Lisboa: Dinalivro, 1994.

BETTI, Mauro; MENDES, Diego de Sousa. Educação Física e Esporte: Perspectivas com as Novas Tecnologias de Informação e Comunicação. In: MOREIRA, W. W; NISTA-PICCOLO, V. L. (orgs). Educação Física e esporte no século XXI. Campinas: Papirus, 2016.

BIANCHI, Paula; PIRES, Giovani De Lorenzi. Possibilidades Para O Ensino-Aprendizagem Com Tics Na Educação Física Escolar : Caderno de Formação RBCE, v. 1, p. 45-55 , 2010.

BODSWORTH, Hannah; GOODYEAR, Victoria A. Barriers and facilitators to using digital technologies in the Cooperative Learning model in physical education. Physical Education and Sport Pedagogy v. 22, mar. 2017. DOI: https://doi.org/10.1080/17408989.2017.129467 $\underline{2}$

BOGDAN, Roberto; BIKLEN, Sari Knopp. Investigação qualitativa em educação: uma introdução à teoria e aos métodos. Porto: Porto Editora, 1994.

BOLONHINI, Sabine Zink; PAES, Roberto Rodrigues. A proposta pedagógica do Teaching Games for Understanding: Reflexões sobre a iniciação esportiva. Pensar a prática, v.12, n.2, p. 1-4, maio/ago. 2009.

BORGES, Robson Machado; DINIZ, Irlla Karla Santos. Voleibol. In: GONZÁLEZ, Fernando Jaime; DARIDO, Suraya Cristina; OLIVEIRA, Amauri A. Bassóli de (orgs.). Esportes de marca e com rede divisória ou muro/parede de rebote. Maringá: Eduem, 2017. p. 375457.

CLEMENTE, Filipe Manuel. Princípios Pedagógicos dos Teaching Games for Understanding e da Pedagogia Não-Linear no Ensino da Educação Física. Movimento, v. 18, n. 2, p. 315335, abr./jun. 2012.

CLEMENTE, Filipe Manuel. Uma Visão Integrada do Modelo Teaching Games for Understanding : Adequando os estilos de ensino e questionamento à realidade da Educação Física. Revista Brasileira de Ciências do Esporte, v. 36, n. 2, p. 587-601, abr./jun. 2014.

COSTA, Israel Teoldo; GRECO, Pablo Juan; MESQUITA, Isabel; GRAÇA, Amândio; GARGANTA, Julio. O Teaching Games for Understanding (TGfU) como modelo de ensino dos jogos desportivos coletivos. Revista Palestra, v. 10, p. 69-77, 2010. 
DAMICO, José. Corpo a corpo com as jovens: Grupos focais e análise de discurso na pesquisa em educação física. Movimento, v.12, n. 2, p. 35-67, maio/ago. 2006.

GALATTI, Larissa Rafaela; REVERDITO, Riller Silva; SCAGLIA, Alcides José; PAES, Roberto Rodrigues; SEOANE, Antônio Montero. Pedagogia do Esporte: tensão na ciência e o ensino dos Jogos Esportivos Coletivos. Revista da Educação Física/UEM, v. 25, n. 1, p. 153-162, 2014.

GONZÁLEZ, Fernando Jaime; BRACHT, Valter. Metodologia do Ensino dos Esportes Coletivos. Vitória: UFES, 2012.

GRAÇA, Amândio; MESQUITA, Isabel. A investigação sobre os modelos de ensino dos jogos desportivos. Revista Portuguesa de Ciências do Desporto, v. 7, n. 3, p. 401-421 , 2007.

HARVEY, Stephen; JARRETT, Kendall. A review of the game-centred approaches to teaching and coaching literature since 2006. Physical Education \& Sport Pedagogy. v.19, n.3, p. 278-300, 2014. DOI: 10.1080/17408989.2012.754005.

HARVEY, Stephen; PILL, Shane; ALMOND, Len. Old wine in new bottles: a response to claims that teaching games for understanding was not developed as a theoretically based pedagogical framework. Physical Education and Sport Pedagogy, v. 23, n. 2, p. 166-180, 2018. DOI: $10.1080 / 17408989.2017 .1359526$.

HASTIE, Peter; MARTINEZ DE OJEDA, Diego; CALDERÓN LUQUIN, Antonio. A review of research on Sport Education: 2004 to the present. Physical Education \& Sport Pedagogy v. 16, n. 2, p. 103-132, 2011.

HIRAMA, Leopoldo Katsuki; JOAQUIM, Cássia Santos; MATOS, José Arlen Beltrão; MONTAGNER, Paulo César. Construção tática no voleibol: ensino pela compreensão. Conexões, v. 13, n. 4, p. 165-177, out./dez. 2015.

IMPOLCETTO, Fernanda; DARIDO Suraya Cristina. Sistematização dos conteúdos do voleibol: possibilidades para a Educação Física escolar. Revista Brasileira de Ciências e Movimento, v.2, n. 19, p. 90-100, 2011.

KIRK, David; MACPHAIL, Ann. Teaching games for understanding and situated learning: rethink-ing the Bunker-Thorpe model. Journal of Teaching in Physical Education, v. 2, n. 21, p. 177-192, 2002.

LAKATOS, Eva Maria; MARCONI, Marina de Andrade. Metodologia do trabalho científico. 5. ed. São Paulo: Atlas, 2003.

LUGUETTI, Carla; GOODYEAR, Victoria Anne; ANDRÉ, Mauro Henrique. "That is like a 24 hours-day tournament!": using social media to further an authentic sport experience within sport education. Sport, Education and Society, v. 24, n. 1,p. 78-91, 2017.

DOI: $\underline{10.1080 / 13573322.2017 .1292235}$

MAHLO, Friederich. O acto táctico no jogo. Lisboa: Compendium, 1980.

MESQUITA, Isabel M. R.; PEREIRA, Felismina Rosa Marques; GRAÇA, Amândio. Modelos de ensino dos jogos desportivos: investigação e ilações para a prática. Motriz, v. 15 n. 4, p. 944-954, 2009.

MINAYO, Maria Cecília Souza. O desafio do conhecimento: Pesquisa qualitativa em saúde. São Paulo: HUCITEC, 2007.

MITCHELL, Stephen A.; OSLIN, Judith L.; GRIFFIN, Linda L. Teaching Sport Concepts and Skills. 3. ed. Bethesda: Human Kinetics, 2013. 
PARLEBAS, Pierre. Juegos, Deporte y Sociedades: Léxico de praxeología motriz. Barcelona: Paidotribo, 2001.

PEARSON, Paul; WEBB, Paul. Developing effective questioning in Teaching Games for Understanding (TGfU). Asia Pacific Sport in Education Conference. $1^{\text {st. }}$ Adelaide, 2008. Disponível em: https://ro.uow.edu.au/cgi/viewcontent.cgi?article=1054\&context=edupapers. Acesso em: 30 jan. 2020.

ROCHA, Marcos Augusto. Estudo das habilidades técnicas do ataque na posição quatro do voleibol. 2009. Tese (Doutorado) - Escola de Educação Física e Esporte, Universidade de São Paulo, 2009.

REVERDITO, Riller Silva; SCAGLIA, Alcides José; PAES, Roberto Rodrigues. Pedagogia do esporte: panorama e análise conceitual das principais abordagens. Motriz, v. 15, p. 600-610, 2009.

SCAGLIA, Alcides José; REVERDITO, Riller Silva; GALATTI, Larissa Rafaela. A contribuição da pedagogia do esporte ao ensino do esporte na escola: Tensões e reflexões metodológicas. In: MARINHO, Alcyane; NASCIMENTO, Juarez Vieira; OLIVEIRA, Amauri Aparecido Bássoli. (orgs). Legados do esporte brasileiro. Florianópolis: UDESC, 2014. p. 45-86.

SILVA JUNIOR, Severino Domingos; COSTA, Francisco José. Mensuração e Escalas de Verificação: uma Análise Comparativa das Escalas de Likert e Phrase Completion. Revista Brasileira de Pesquisas de Marketing, Opinião e Mídia, v. 15, p. 1-16, out. 2014. Disponível em: http://sistema.semead.com.br/17semead/resultado/trabalhosPDF/1012.pdf. Acesso em: 22 jan. 2019.

SOUZA, Adriano José. Ensinando e desenvolvendo o esporte na escola: o caso do voleibol. (Monografia) - Faculdade de Educação Física, Universidade Estadual de Campinas. Campinas, 1996.

SOUZA, Carlos Raphael Braga Corrêa; MÜLLER, Ezequiel Steckling; COSTA, Israel Teoldo. Quais comportamentos táticos de jogadores de futebol da categoria sub-14 podem melhorar após 20 sessões de treino? Revista Brasileira de Ciências do Esporte, v. 36, n. 1, p. 1186, jan./mar. 2014.

SPARKES, Andrew C; SMITH, Brett. Qualitative research methods in Sport, Exercise and Health. London: Routledge, 2014.

THORPE, Rod; BUNKER, D; ALMOND, L. Rethinking games teaching. Leicstershire: University of Loughborough, 1986.

Apoio:

Serviço Social do Comércio (SESC/SP) 